\title{
Pena (Teoría de la) Punishment (Theory of)
}

\author{
Daniel Rodríguez Horcajo \\ Universidad Autónoma de Madrid \\ daniel.rodriguez@uam.es
}

Recibido / received: 23/11/2018

Aceptado / accepted: 15/02/2019

DOI: https://doi.org/10.20318/eunomia.2019.4701

\begin{abstract}
Resumen
La teoría de la pena está constituida por dos elementos que han sido tratados por la doctrina de una manera desigual. En primer lugar, dicha teoría trata de definir qué debe ser entendido como 'pena', para poder diferenciarla de otras sanciones (formales o informales). En segundo lugar, se ocupa de justificar en términos abstractos una intervención estatal de tanta magnitud sobre la esfera individual, optando por teorías absolutas, por teorías preventivas o por algún tipo de posición intermedia entre unas y otras.
\end{abstract}

\section{Palabras clave}

Pena, retribución, prevención general, prevención especial.

\begin{abstract}
The theory of punishment is constituted by two elements that have been studied by the doctrine in an unequal way. In the first place, this theory tries to define what should be understood as 'punishment', in order to differentiate it from other sanctions (formal or informal ones). Secondly, it deals with justifying, in abstract terms, a state intervention of such magnitude on the individual sphere, opting for absolute theories, for preventive theories or for some kind of intermediate position between one and the other.
\end{abstract}

\section{Keywords}

Punishment, retribution/desert, general prevention, special prevention.

SUMARIO. 1. Introducción. 2. Concepto de 'pena'. 3. Justificación de la pena. 3.1. Teorías absolutas. 3.2. Teorías relativas. 3.2.1. Prevención general. 3.2.2. Prevención especial. 3.3. Teorías eclécticas. 4. Conclusiones 


\section{Introducción}

La teoría de la pena se encarga de dar respuesta a una pregunta básica para cualquier sistema jurídico: ¿por qué aceptamos como correcto (por qué consideramos como justificado) que el Estado pueda imponer una pena a los sujetos que han cometido un delito?, ¿por qué el Estado puede en esos supuestos causar un mal a dichos individuos? Aunque optar por una reacción distinta podría parecer absurdo (por ejemplo, dejar pasar el hecho como si fuese irrelevante u otorgar una ventaja al sujeto que muestra un comportamiento desviado), ello no impide que una injerencia tan fuerte en la vida de determinados ciudadanos requiera de una argumentación subyacente igualmente de calado. Además, esto toma especial sentido en los ordenamientos jurídicos modernos, en los que la pena se ha convertido en la consecuencia jurídica del delito por excelencia (tome la forma que tome: privación de libertad, privación de patrimonio, inhabilitación,...) frente a las excepcionales y secundarias medidas de seguridad y consecuencias accesorias del delito.

Este tema ha ocupado a las mejores mentes de la Filosofía y del Derecho penal en los últimos milenios, por lo que hacer un esquema sencillo y breve no es sino, como poco, ser algo injusto. En todo caso, y como bien defendió Hart, para construir una teoría de la pena no basta simplemente con argumentar la justificación de la misma, sino que se debe partir de un presupuesto básico: un concepto determinado de 'pena' (Hart, 1968a: 3-4). Por ello, en este trabajo se va a desarrollar esa "doble perspectiva" de análisis, abordando en primer lugar la cuestión conceptual para después pasar al análisis jurídico-filosófico de la pertinencia de dicha institución.

\section{Concepto de 'pena'}

Desde un punto de vista estrictamente lingüístico, la Real Academia Española de la Lengua define el concepto 'pena', en sus segunda y tercera acepciones, como "castigo impuesto conforme a la ley por los jueces o tribunales a los responsables de un delito o falta", y como "dolor, tormento o sentimiento corporal" (RAE, 2017). Desde un punto de vista jurídico-penal, y a pesar de lo contradictorio que pueda parecer, se carece por completo de un concepto análogo, ya que el Código Penal (en adelante, CP) opta simplemente por establecer una clasificación de las distintas penas en él previstas y por excluir de dicho concepto a ciertas injerencias en la esfera personal de los ciudadanos. Según los arts. 32 y $33 \mathrm{CP}$, las penas pueden ser principales o accesorias; privativas de libertad, privativas de otros derechos, o de multa; y también pueden ser graves, menos graves y leves ${ }^{1}$. Por lo demás, el art. $34 \mathrm{CP}$ excluye del concepto de 'pena' tanto a las medidas cautelares acordadas en el proceso penal, como a las sanciones administrativas y a las "privaciones de derechos y sanciones" con finalidad reparadora (sean civiles o administrativas).

Frente a esta indefinición legal, la jurisprudencia del Tribunal Europeo de Derechos Humanos (en adelante, TEDH), en sede de garantías derivadas del principio de legalidad (art. 7 del Convenio Europeo de Derechos Humanos -en adelante, $\mathrm{CEDH}-$ ), ha elaborado una caracterización casuística del concepto de 'pena', y en todo caso autónoma frente a los ordenamientos nacionales de los

\footnotetext{
${ }^{1}$ Conforme al art. $13 \mathrm{CP}$, esto último también es relevante para determinar si un concreto delito debe ser considerado como grave, menos grave o leve.
} 
Estados del Consejo de Europa. El denominado "test Welch" ${ }^{2}$ toma en consideración inicialmente, a los efectos de considerar una medida sancionadora nacional como 'pena' vinculada al art. $7 \mathrm{CEDH}$, que la misma sea subsiguiente a una condena por la comisión de un hecho penalmente relevante. A partir de ahí, también atiende a la naturaleza y finalidad de la medida, a su caracterización conforme al Derecho nacional, a su procedimiento de ejecución y a su severidad ${ }^{3}$.

Esta aproximación, parcial (pues sólo se ha dictado en sede de principio de legalidad) y no concluyente (pues no aporta un concepto cerrado), tampoco parece suficiente $^{4}$, por lo que la vía más asentada para encontrar una definición de este concepto es el recurso a la doctrina, que, aunque no de manera muy abundante, ha hecho incursiones suficientes en esta materia. A pesar de que existen algunas discrepancias $^{5}$, entiendo que el concepto central de la pena es el de mal (dolor, restricción o privación de bienes jurídicos) ${ }^{6}$. Partiendo de esto, quizás la definición de 'pena' que más éxito ha cosechado ha sido la de Hart (1968: 4-5), que hace constar a esta institución de cinco rasgos esenciales: es una medida que (1) implica sufrimiento u otras consecuencias normalmente aceptadas como desagradables; (2) se impone por un comportamiento contrario a normas jurídicas; (3) se impone sobre el sujeto culpable de dicho comportamiento; (4) se ejecuta de manera intencional por un tercero distinto al culpable; y (5) se impone y ejecuta por una autoridad constituida por el sistema jurídico contra el cual se ha cometido la infracción ${ }^{7}$. Estas características han llevado a Peñaranda Ramos a sintetizar la siguiente definición: "La pena (criminal) es una privación o restricción de bienes jurídicos, prevista por la ley e impuesta por los órganos jurisdiccionales competentes a través del procedimiento legalmente establecido, como castigo por la realización de un hecho jurídicamente desaprobado y constitutivo de delito a aquél a quien se considera responsable de su comisión" (2015: 259). Quizás, a esa definición de corte hartiano cabría añadirle una última caracterización: la pena no es sólo un mal, sino que es así por su propia naturaleza, es decir, el sufrimiento ínsito en la misma es su esencia, de tal modo que si se hiciese desaparecer, la pena dejaría de serlo (Nino, 1980: 173).

\footnotetext{
2 Por haber sido enunciado por primera vez en la STEDH as. Welch c. Reino Unido, de 9 de febrero de 1995, párs. 27-28.

3 SSTEDH as. Kafkaris c. Chipre, de 12 de febrero de 2008, pár. 142; as. M c. Alemania, de 17 de diciembre de 2009, pár. 120; as. Del Río Prada c. España, de 21 de octubre de 2013, pár. 82; as. G.I.E.M. S.R.L. y otros c. Italia, de 28 de junio de 2018, párs. 210-211. En profundidad sobre esta cuestión, vid. Rodríguez Horcajo (2013: 265-266 y 272-280).

4 Tampoco resulta de especial utilidad nuestra jurisprudencia constitucional a este respecto, ya que la misma ha abordado sólo parcialmente esta cuestión en el seno de la interdicción del bis in idem. En ese sentido, lo que ha preocupado al Tribunal Constitucional no ha sido sólo la concurrencia de dos penas sino la de dos sanciones, por lo que es ese último concepto el que ha sido elaborado por el mismo (sobre esta cuestión, vid. Pérez Manzano [2010: 33-34]). Es cierto que también se ha planteado un problema parecido con relación al principio de legalidad (principio de personalidad de las penas vinculado al principio de culpabilidad, mandato de determinación, mandato de predeterminación,...) y con relación al derecho a la tutela judicial efectiva, pero en esos casos el Tribunal Constitucional ha vuelto a dedicarse a la elaboración de un concepto de 'sanción' que no es necesariamente coincidente con el de 'pena' (vid. por ejemplo, las más recientes SSTC 60/2010, de 7 de octubre, y 185/2016, de 3 de noviembre). Sobre esta cuestión, vid. Rodríguez Mourullo (2002: 99-103); Lascuraín Sánchez (2009: 44-48); el mismo (2018: 354-356),. Aunque no se pueda profundizar aquí, lo cierto es que me parece especialmente desacertada esa idea constitucional recurrente (y repetida también por gran parte de la doctrina) de vincular el concepto de sanción con la finalidad de la restricción de bienes jurídicos que se analiza en cada caso, porque esto implica introducir en la propia definición cuestiones que se deben analizar en el momento de justificar dicha institución.

${ }^{5}$ Hegel (1821: §99); Jakobs (1991: 6).

${ }^{6}$ Tradicionales, Feuerbach (1799: 5); Bentham (1830: 49). Más reciente, Zaibert (2015: 147); el mismo (2018: 1).

${ }^{7}$ Muy similar, Nino (1980: 168-173). Sobre esta cuestión, vid. Betegón Carrillo (1992: 141-203).
} 
Sin embargo, en todas estas definiciones hay algo más que un planteamiento neutro del concepto, pues, por un lado, avanzan criterios que sólo pueden predicarse de algunas sanciones penales (o, en todo caso, de las sanciones de algunos sistemas penales), y, por el otro, introducen también matices relativos a la finalidad de la pena que, en el mejor de los casos, deben ser tratados en el momento de justificarla pero no en el de definirla. Ambas cuestiones se mezclan claramente, por ejemplo, en el tercer requisito exigido por Hart, ya que él sólo considera 'pena' a aquella restricción que cumple con el principio de culpabilidad. Sin embargo, esto no es generalizable a todos los ordenamientos penales y se vincula inexorablemente con el concepto de merecimiento, que es central en alguna justificación de la pena pero no en otras ${ }^{8}$.

Se trata, por tanto, de elaborar un concepto que no sea ni infra-inclusivo ni supra-inclusivo, es decir, que no sea inútil pero que tampoco cancele ciertas discusiones que se deben producir con relación al segundo estadio de la teoría de la pena $^{9}$. Personalmente creo que el mismo debe tomar en consideración las siguientes notas: La pena (1) implica necesariamente la imposición de un mal (privación o restricción de bienes jurídicos) de manera querida; (2) frente a la realización de una conducta jurídicamente desaprobada considerada materialmente como delito; (3) por parte de los jueces y tribunales competentes según el ordenamiento jurídico transgredido, y (4) siguiendo en todo caso las reglas formales previstas en el mismo ${ }^{10}$.

\section{Justificación de la pena}

\subsection{Teorías absolutas}

Partiendo de un concepto determinado de 'pena', se puede pasar a estudiar las respuestas que se han dado a la pregunta que se planteaba en la introducción. En general, y dejando de lado las propuestas abolicionistas (que no pretenden justificar al sistema penal, sino hacerlo desaparecer por ilegítimo), se puede seguir la máxima de Grocio (1625: 67) en la que se resumen las dos grandes formas de abordar este problema: "Nemo prudens punitur quia peccatum est sed ne peccetur"11. Aunque su planteamiento no fue meramente expositivo con relación a estas dos posibilidades, al menos sí que parceló la discusión de un modo que ha sido seguido hasta la actualidad, y que hace descansar la justificación de la pena en una perspectiva de pasado (mirando al delito cometido y desvinculándose de fines distintos a su propia represión) o en una perspectiva de futuro (de consecución de beneficios, individuales o grupales) (Zaibert, 2015: 147).

\footnotetext{
${ }^{8}$ No hay que dejar de ver tampoco que la exigencia de un requisito como este tiene una especial bondad en los sistemas penales de doble vía, pues permite diferenciar de manera clara entre penas y medidas de seguridad.

${ }^{9}$ Sobre los problemas del denominado 'definitional stop', vid. Hart (1968 a : 5-6); Betegón Carrillo (1992: 172-193; Rodríguez Mourullo (2002: 96-97).

${ }^{10}$ En un sentido muy similar, vid. Greco (2009: 299-303). El criterio de culpabilidad o responsabilidad por el hecho jurídicamente desaprobado (que aparece de manera mayoritaria en las definiciones ofrecidas por la doctrina) simplemente debe ser una nota relevante en aquellos ordenamientos jurídicos que distinguen entre pena y medida de seguridad, pero esto no afecta a la definición de la primera sino a la separación ad intra de estos dos instrumentos (no encuentro mayor problema, todavía en este punto, en considerar la medida de seguridad como una pena que tiene un fundamento distinto a la culpabilidad). Si un ordenamiento no prevé esta segunda institución, no cabe duda de que toda sanción estatal que cumpla con los requisitos precitados debe ser considerada como pena y, en ese sentido, debe iniciarse la discusión acerca de su justificación y del sometimiento de la misma a las garantías que sean pertinentes.

${ }^{11}$ Mucho antes, Platón (384: 47).
} 
La opción de "punitur quia peccatum est" se ha equiparado con las denominadas teorías absolutas de la pena, que encuentran la bondad de esta institución en sí misma y no en sus consecuencias ( $y$, en esa medida, se separan de las teorías relativas, que destacan la capacidad de la pena para alcanzar determinadas finalidades en una cantidad suficiente). Su idea de base es bastante sencilla: para los autores que defienden esta postura imponer un mal a quien ha realizado otro mal con anterioridad es algo justo, siendo esto suficiente para soportar la estructura penal (aunque de la amenaza e imposición de la pena no se obtengan otros fines adicionales).

Aunque se pueden encontrar otras teorías absolutas, las principales son las teorías de la retribución o del merecimiento ${ }^{12}$, que, aunque no son un cuerpo unitario, sí que destacan lo correcto de imponer una pena de una determinada cuantía al sujeto que cometió un delito ("Responde a la arraigada convicción de que el mal no debe quedar sin castigo y el culpable debe encontrar en él su merecido" [Mir Puig, 2016: 84]). Siguiendo a Mir Puig, las teorías retributivas pueden tener una triple fundamentación: religiosa, ética y jurídica (2016: 84). Dejando de lado la primera, que no parece ser relevante a efectos jurídicos, los máximos exponentes de cada una de las otras dos fundamentaciones fueron dos filósofos alemanes: Kant y Hegel, respectivamente.

Para Kant, que parte del tradicional presupuesto contractualista predominante en el s. XVIII (1797: 141-147), "la pena judicial (poena forensis) [...] no puede nunca servir simplemente como medio para fomentar otro bien, sea para el delincuente mismo sea para la sociedad civil, sino que ha de imponérsele sólo porque ha delinquido; porque el hombre nunca puede ser manejado como medio para los propósitos de otro ni confundido entre los objetos del derecho real [de los derechos reales]" (1797: 166). La pena, así entendida, es un imperativo categórico, $\mathrm{y}$, por tanto, sólo puede mirar al pasado y castigar en el momento presente siguiendo criterios de justicia ("porque si perece la justicia, carece ya de valor que vivan los hombres sobra la tierra" [1797: 167]), haciendo que el delito (como manifestación de la injusticia) recaiga sobre la persona que merece reproche (el delincuente) y no sobre el resto de la sociedad (sobre el que recaería la conducta injusta si no reclamase un castigo a la misma [1797: 169]).

Esta exigencia de punición (esta obligatoriedad de la misma), que llega hasta el final de la existencia de la propia sociedad en la que convive el delincuente ${ }^{13}$, tiene ante todo una característica particular: el principio de igualdad entre delito y pena, lo que se ha venido a denominar, siguiendo su formulación tradicional, como lex talionis. Para Kant este es el único criterio de determinación de la pena que puede asegurar una resolución justa del conflicto (1797: 167).

El segundo autor referente en relación con las teorías retributivas es Hegel. Para él la pena es una segunda coerción (justificada) que realiza la superación de una previa ${ }^{14}$, en tanto que esta primera supone una exteriorización de la voluntad particular injusta del delincuente que pretende imponerse a la voluntad general recogida en la norma infringida (1821: §99). La pena es así afirmación del Derecho

\footnotetext{
12 Hay que destacar aquí que la mayoría de la doctrina identifica teorías absolutas con teorías retributivas, lo que desde mi punto de vista no es del todo correcto (así, por ejemplo, Roxin [2006: 70 y ss.]; Stratenwerth/Kuhlen [2011: 4 y ss.]; Peñaranda Ramos [2015: 262 y ss.]). Sobre ello, vid. Rodríguez Horcajo (2016: 29-31).

${ }^{13}$ Es así paradigmático el ejemplo kantiano clásico de la isla, en el que este autor destaca la necesidad de ejecutar hasta al último asesino que se encuentre en prisión antes de que la sociedad que habita dicho espacio se disuelva y sus integrantes se dispersen por el mundo (vid. Kant [1797: 168-169].

${ }^{14}$ La vulneración de una obligación jurídica es vista por Hegel como una coacción (vid. Hegel, [1821: §93.1]).
} 
("negación de la negación" [1821: §104]) a costa del infractor (1821: §100), sin atender a consecuencias más allá del propio castigo ${ }^{15}$. Se trataría "de la restauración del orden jurídico (voluntad general) conmovido por el delito: la conmoción producida por la voluntad especial del delincuente persiste en el mundo mientras no se suprima o cancele con la imposición de la pena y es el verdadero perjuicio que el Derecho Penal tiene que suprimir, porque, si esa cancelación no se diera, sería el delito y no el Derecho lo que continuaría manifestándose como efectivamente vigente hacia el futuro" (Peñaranda Ramos, 2015: 164). De ahí que la retribución hegeliana sea una retribución de fundamentación jurídica ${ }^{16}$.

Sin embargo, Hegel se separa de Kant a la hora de cuantificar la pena justa, ya que, aunque sigue hablando de igualdad entre delito y pena, no se refiere a "la igualdad en la naturaleza específica de la vulneración, sino en la naturaleza de la vulneración en sí misma atendiendo a su valor" (1821: §101). Esto parece acercar su postura a una defensa de la proporcionalidad (Klug, 1968: 38; Roxin, 2006; 72), es decir, de la comparación de valor (y no de cuantía exacta) entre delito y pena ${ }^{17}$.

$\mathrm{Y}$, aunque pueda ser vista como una teoría en exceso abstracta, lo cierto es que el pensamiento retributivo goza de un amplio apoyo social ${ }^{18}$. Además, esta teoría tiene potencialidad para limitar en términos deontológicos el castigo estatal ${ }^{19}$, ya que reduce la pena justificada a aquella que se impone sobre el sujeto culpable y en una cuantía proporcional a la del injusto delictivo (objetivo y subjetivo), rompiendo de manera radical con cualquier cálculo consecuencialista ajeno a esta lógica.

En todo caso, la gran mayoría de la doctrina considera estas ventajas como insuficientes si se comparan con los problemas a los que se enfrenta una visión absoluta de una institución social como la pena ${ }^{20}$. Resumidamente, la explicación retributiva de la misma esconde tras de sí un acto de "alquimia moral" en el que una acumulación de males (el del delito y el de la pena) acaban transformados en algo bueno ( $\mathrm{y}$ sin referenciarse a beneficios futuros, explicar esta cuestión parece más que complejo ${ }^{21}$. Además, estas teorías arrastran todos los problemas que han surgido en torno a la idea de libre albedrío ${ }^{22}$, y cargan con un tono moralizante (más

\footnotetext{
15 Resulta muy discutible que la afirmación del Derecho no suponga ya la consecución de un fin diferente a la propia imposición de la pena, por lo que es dudoso que Hegel pueda seguir siendo considerado como un autor retribucionista (vid., por ejemplo, Mir Puig [2011: 37]; Peñaranda Ramos [2015: 265]. Esto parece ser confirmado por muchos teóricos de la prevención general positiva, que toman a Hegel como origen de su planteamiento pero que a la vez defienden la capacidad preventiva de la pena. El caso más paradigmático de esto último es el de Jakobs (vid. Jakobs [1991: 17]; el mismo [2006: 129-151]). Sobre esta cuestión vid. Rodríguez Horcajo (2016: 209-218).

${ }^{16}$ Es discutible que en Kant no haya también algo de fundamentación jurídica de la retribución, pues, entre otras cosas, afirma, en un sentido muy similar a Hegel pero de modo colateral, que "quien roba hace insegura la propiedad de todos los demás" (Kant, 1797: 168), lo que puede ser entendido como una erosión de la vigencia real de la norma que debe ser remediada.

17 En cualquier caso, tanto la postura de Kant como la de Hegel cumplirían los tres rasgos que para Hart caracterizan a cualquier teoría retributiva: el castigo sólo puede ser impuesto ante la realización voluntaria de algo moralmente malo; el castigo debe ser equivalente a la maldad de la conducta; y la justificación del castigo reside en la idea de que el sufrimiento impuesto por la comisión voluntaria de un acto moralmente malo es algo en sí mismo justo o bueno (vid. Hart [1968b: 231]).

18 Roxin (2006: 72); Stratenwerth/Kuhlen (2011: 4); Mir Puig (2016: 84). Especialmente, Robinson (2008: 202-204; 2012: 23-54, y 2013: 18-34). Sobre esta cuestión, vid. Rodríguez Horcajo (2016: $165-$ 174).

${ }^{19}$ Equiparan retribución con garantismo, por ejemplo, Rodríguez Mourullo (1978: 54); Roxin (2006: 72); Hassemer (2009: 71-72); Peñaranda Ramos (2015: 264-265); Mir Puig (2016: 86).

20 Para un análisis racionalista de estas teorías con las consecuentes críticas, vid. Klug (1968: 39-41). También, Rodríguez Horcajo (2016: 198-205).

${ }^{21}$ Hart (1968b: 234-235); Nino (1989: 43); Roxin (2015: 188-189). Antes ya, Bentham (1830: 62).

22 Pérez Manzano (1990: 67-132); Molina Fernández (2002: 71-175).
} 
o menos neutro, según los casos) que las hacen incompatibles con un ordenamiento penal depurado de estas cuestiones.

\subsection{Teorías relativas}

Frente a las teorías absolutas (y frente a sus problemas) surgen las denominadas teorías relativas, que justifican la pena por su orientación hacia fines ajenos a ella misma y, especialmente, por su capacidad para prevenir delitos futuros. Esta es la manera de romper con la "alquimia moral" retributiva, ya que la consecución de fines positivos de mayor valor es lo que hace soportable la amenaza de un mal y su imposición a un sujeto concreto.

A partir de ahí, las teorías preventivas gozan de una riqueza inmensa que puede categorizarse siguiendo dos binomios distintos: por un lado, el binomio prevención general/prevención especial; por el otro, el binomio prevención negativa/prevención positiva. Mientras que en el primero lo que se encuentra en juego es la pretensión de prevención de delitos que se asigna a la pena (una que se dirige a todos los miembros de la sociedad -prevención general- o una que se dirige al sujeto efectivamente condenado para que no reincida -prevención especial-), en el segundo lo que se discute son los medios para alcanzar dicha prevención (represivos -prevención negativa- o "benignos" -prevención positiva-).

\subsubsection{Prevención general}

Quizás las primeras teorías estructuradas de la prevención ${ }^{23}$ fueron aquellas que pueden ser consideradas como teorías de la prevención general negativa (disuasión), ideadas por dos autores contemporáneos entre sí: Feuerbach y Bentham ${ }^{24}$. Para el autor alemán, ante la imposibilidad real de que el Estado garantice la coexistencia de los ciudadanos simplemente recurriendo a intervenciones físicas (Feuerbach, 1847: 37), este debe optar por neutralizar la "sensualidad de la transgresión de la norma" (1799: 43) con la amenaza de un mal de imposición posterior a la misma (1799: 45-47; 1847: 38). La pena, entonces, operaría frente a la generalidad de las personas a modo de coacción psicológica disuadiendo de la comisión de delitos. Esta operación se articularía en dos fases: en primer lugar, mediante la conminación legal $\mathrm{y}$, en segundo lugar, mediante la ejecución de la pena correspondiente (1799: 49-52). El primer paso sería el conducente a la intimidación general, mientras que el segundo devendría necesario para mantener la eficacia (la credibilidad) de la amenaza contenida en la ley (1847: 38-39).

Por su parte, Bentham, en unos términos profundamente utilitaristas ${ }^{25}$, basa la capacidad protectora de bienes jurídicos del Derecho penal en un recurso cotidiano en el día a día: el miedo a un posible castigo en caso de comisión de un

\footnotetext{
${ }^{23}$ Sin dejar de ver que el germen de estas posiciones estaba ya en el Protágoras de Platón, en el que el filósofo griego resumió toda la discusión prácticamente en una frase: "El que intenta castigar con razón no se venga a causa del crimen cometido -pues no se lograría hacer que lo hecho no haya acaecido-, sino con vistas al futuro, para que no obren mal de nuevo ni éste mismo ni otros, al ver que éste sufre el castigo" (384: 47).

${ }^{24}$ Aun así, antes que ellos Beccaria ya había puesto las bases de una teoría de la prevención general. Ello resulta evidente cuando se observan los criterios que a su parecer determinan la eficacia de una pena preventiva y que parecen otorgarle una pretensión general y disuasoria: además de la cuantía de la misma, resulta importante para dicho fin tanto la probabilidad de que efectivamente la pena amenazada se acabe imponiendo como la distancia temporal que existe entre el momento de la comisión del delito y el de la imposición de la pena (Beccaria, 1764: 57 y 69).

25 "Todo castigo siendo en sí mismo un mal, bajo el principio de utilidad, si debe ser admitido, debe serlo en tanto que se tenga la esperanza de evitar un mal mayor" (Bentham, 1830: 63).
} 
delito, generando en los sujetos razones instrumentales para cumplir con las normas penales (que se cifran fundamentalmente en la evitación de la sanción) ${ }^{26}$. Este miedo dependería así de la severidad de la pena, pero también del grado de certeza que exista en la detección y enjuiciamiento del delito, y de la celeridad con que se imponga la pena tras dicha comisión ${ }^{27}$. Además, y como "mecanismo psicológico", el temor no se basa en estas tres magnitudes contabilizadas de forma objetiva, sino que la disuasión es mayor o menor en función de la percepción subjetiva (individual o grupal) de la severidad, certeza y celeridad de la sanción. Y aún más allá, la disuasión dependería de la desutilidad subjetiva que para cada sujeto se derive de su percepción de esas magnitudes (Bentham, 1830: 61-75).

Y aunque ambas teorías son muy similares, es importante destacar que mientras que para Feuerbach lo central de la pena es el momento de la amenaza y su funcionamiento como mecanismo psicológico primitivo, para Bentham lo importante es la imposición del dolor y su funcionamiento como mecanismo prudencial (económico en un sentido amplio) (Peñaranda Ramos, 2015: 267-268: Mir Puig, 2016: 88).

Sin embargo, especialmente desde mediados del s. XX se produjo una reacción fuerte frente a visiones preventivogenerales como la de Bentham o Feuerbach, que fueron acusadas de justificar un verdadero "terror penal" (Roxin, 2006: 83; Peñaranda Ramos, 2015: 217). La consecuencia fue la de afirmar que la prevención general podía alcanzarse por métodos más sutiles, no reprimiendo a los potenciales delincuentes sino afirmando positivamente el propio Derecho frente a la totalidad de la sociedad (Mir Puig, 2016: 89). Esta "nueva" visión fue denominada como prevención general positiva y rápidamente se disgregó en teorías tan diversas que son imposibles de esquematizar aquí ${ }^{28}$.

Quizás por ser la teoría de la prevención general positiva más estudiada, merece mencionarse la visión, también muy cambiante durante los últimos años, de Jakobs. Para este autor, que no plantea algo muy distinto a lo que avanzara Carrara a finales del s. XIX ${ }^{29}$, la pena operaría como sistema que reafirma la confianza de la sociedad en las normas vigentes frente a la desautorización de las mismas contenida en su infracción ${ }^{30}$. A partir de ahí, Jakobs ha ido depurando su teoría de determinados elementos para quedarse en una visión tremendamente abstracta

\footnotetext{
${ }^{26}$ Es cierto que este autor no descarta tampoco los posibles efectos preventivoespeciales derivados de la pena (que él distingue entre incapacitación, reforma moral e intimidación), pero que en ningún caso pueden servir para justificar dicha institución ("La prevención general debe ser el objetivo principal del castigo, así como su justificación real" [Bentham, 1830: 62]).

${ }^{27}$ En este sentido, Bentham observa el problema desde el mismo punto que lo había hecho Beccaria, eliminando esa vinculación exclusiva que permanentemente se ha realizado entre disuasión y cuantía de pena.

${ }^{28}$ Para una clasificación ordenada de las mismas, vid. Feijoo Sánchez (2007: 261-512).

${ }^{29}$ Carrara basa la existencia y justificación de la pena en su necesidad para el "mantenimiento de la soberanía del derecho" como medio de garantía de la libertad humana, a primera vista, con unos postulados muy parecidos a los de Hegel: "Exprésese esta idea con la fórmula de que el delito es la negación del derecho y la pena su reafirmación [...] el concepto no es sino uno: el derecho es soberano del mundo moral y cualquiera otra institución es instrumento suyo" (Carrara, 1870: 7). Para el autor italiano, el delito tiene fundamentalmente dos efectos sociales: por un lado, disminuye la tranquilidad de los ciudadanos; por otro, crea el peligro del mal ejemplo. Frente a esto, la pena reestablece el orden violado y regenera la tranquilidad perdida, pero sólo en cuanto que esto es necesario para lo que él denomina, un tanto equívocamente, "tutela jurídica", que no es más que, en términos más modernos, el mantenimiento de la vigencia de las normas penales (Carrara, 1870: 6971).

30 Entendiendo 'vigencia' como 'vigencia real', es decir, como capacidad para regir de hecho las relaciones sociales (como "su realidad social, como determinación de la estructura de la sociedad tal y como acontece"), y no meramente como vigencia jurídica (Jakobs, 2005: 344-345).
} 
(tanto que él ya se considera como un defensor de una teoría absoluta ${ }^{31}$ ) y simbólica: partiendo de la idea de reparación del daño causado por el delito desde la perspectiva general (que contiene un mensaje de desautorización de la norma), la pena supone la respuesta inversa en el mismo plano comunicacional (2005: 342). Para que los contactos sociales sigan existiendo es necesario mantener de manera contrafáctica (es decir, a pesar de su negación fáctica, a pesar del delito), al menos parcialmente, las expectativas generales de comportamiento (Jakobs, 2005: 345347 ), y eso se consigue a través de la pena (que aporta un "apoyo cognitivo de la expectativa de la norma" [Jakobs, 2005: 347]). En resumen: "el autor ha determinado y ejecutado su conducta sin consideración de la vigencia del Derecho. En la medida en que ello implique la afirmación de que la norma no le vincula, se le contradice a través de la pena (ese es el significado de la pena)" (Jakobs, 2006: 142).

\subsubsection{Prevención especial}

Frente a la prevención general, la prevención especial elabora la justificación de la pena con base en el esfuerzo que realiza ante el sujeto que ya ha delinquido: resumidamente, "la pena busca [...] evitar que quien la sufre vuelva a delinquir" (Mir Puig, 2016: 91). Esta idea de prevención "modesta", en el sentido de dirigida a una pequeña parte de la población que carga con el prejuicio de la peligrosidad criminal, parte de las ideas de la alemana Escuela sociológica del Derecho penal y, muy especialmente, de su líder, Franz Von Liszt (Roxin, 2006: 74-75; Peñaranda Ramos, 2015: 281; Mir Puig, 2016: 91; Kindhäuser, 2017: 3) ${ }^{32}$. Este autor defiende, dentro de su concepto de "pena-fin" (1883: 31) y basándose en los efectos reales que la coacción penal tiene frente al delincuente, que esta institución estatal disminuye las probabilidades de reincidencia a través de tres mecanismos: "corrección, intimidación e inocuización" (1883: 34). Cada uno de ellos alcanzaría la prevención especial con relación a un concreto tipo de delincuente: el primero, frente a delincuentes necesitados y capaces de corrección; el segundo, frente a delincuentes no necesitados de corrección; y, el tercero, frente a delincuentes incapaces de corrección (1883: 36). Y, siguiendo la clasificación tradicional, la corrección (resocialización, rehabilitación) sería la manifestación de la prevención especial positiva, mientras que la intimidación y la inocuización serían la muestra de la prevención especial negativa ${ }^{33}$.

Tanto las teorías de la prevención especial como las de la prevención general poseen la evidente bondad de superar la "irracionalidad" que se esconde tras los planteamientos retributivos, ya que defienden la imposición de un mal para la consecución de un bien de mayor entidad. Sin embargo, correlativamente y junto

\footnotetext{
31 Jakobs (1997: 107). Últimamente, de manera más franca, Jakobs ha pasado a hablar de "retribución relativa" (Jakobs, 2012: 15).

32 Esto se afirma sin olvidar que, en esa misma época, el Positivismo Criminológico italiano también defendía una línea de intervención penal similar e incluso de una manera más coherente: "El positivismo criminológico italiano [...], llevó los principios de la prevención especial a su última consecuencia: la sustitución de las penas por las medidas de seguridad. Con ello renunció a influir en la concepción de la pena, cuya idea misma rechazaba. En cambio, el eclecticismo de von Liszt, al respetar la presencia de la pena en los Códigos, pudo ejercer amplia influencia en las teorías penales y en las numerosas reformas de signo "político-criminal' introducidas en las legislaciones del siglo XX" (Mir Puig, 2011: 44).

${ }^{33}$ Desde el punto de vista español, la vertiente de la prevención especial positiva tiene una implicación constitucional, ya que el art. 25.2 CE establece que "las penas privativas de libertad y las medidas de seguridad estarán orientadas hacia la reeducación y reinserción social". Este precepto, que podría marcar un hecho diferencial en la teoría de la pena del Derecho penal español, ha perdido esa capacidad debido a la lectura reduccionista que del mismo ha hecho el Tribunal Constitucional (vid. por ejemplo, SSTC 160/2012, de 20 de septiembre, y 128/2013, de 3 de junio). Más en profundidad, vid. Rodríguez Horcajo (2016: 283-285).
} 
con los problemas específicos que pueden tener cada una de estas visiones particulares, las teorías relativas encuentran siempre enfrente tanto la crítica de origen kantiano sobre el olvido de la naturaleza del ser humano como fin en sí mismo (Kant, 1797: 166-167), como la crítica de origen garantista sobre su potencialidad expansiva ( $\mathrm{y}$, en esa medida, su tendencia a tensionar $\mathrm{u}$ olvidar principios fundamentales del Derecho penal como el de culpabilidad 0 proporcionalidad en aras de una mejor o mayor prevención).

\subsection{Teorías eclécticas}

Ante las insuficiencias que muestran y los problemas de los que adolecen las distintas justificaciones de la pena, la práctica totalidad de la doctrina moderna encuentra un acuerdo fuerte en torno al eclecticismo en esta materia ${ }^{34}$. $Y$ dentro de esto, lo más habitual es afirmar la justificación preventiva de la pena (con más o menos acento en una teoría específica) pero aceptar simultáneamente la idea de merecimiento como una central para esta institución, evitando lo más absoluto de las teorías absolutas (su no referencia a fines) y lo más preventivo de las teorías preventivas (su potencial no garantista). Lo normal entonces es que la retribución juegue un papel negativo ${ }^{35}$, como límite, frente a la finalidad de reducción de delitos, de tal modo que la pena pretenda este objetivo pero sin desatender ideas como las de proporcionalidad y culpabilidad.

Esto se ha conseguido de muy distintos modos, aunque quizás pueden diferenciarse dos grandes formas de limitar la prevención mediante el merecimiento: en la Europa continental lo tradicional ha sido hablar de prevención con límite en la culpabilidad $^{36}$, mientras que en los países anglonorteamericanos se ha impuesto la idea de utilizar el merecimiento como criterio de distribución del castigo ${ }^{37}$. Por otro lado, teorías un tanto más heterodoxas, como, por ejemplo, las teorías expresivas de la pena, han desembocado también en una solución de prevención con límites, ya que el presupuesto básico de cualquiera de ellas es la consideración moral del sujeto delincuente, al que se le manifiesta desaprobación por su acto pero al que se le sigue tratando de acuerdo a su dignidad ${ }^{38}$.

En los últimos años también se observan intentos, cada vez más numerosos, de construir una teoría mixta desde la propia retribución, que ya no jugaría un papel limitador sino uno central, pero que no obviaría la consecución de resultados valorados como positivos. El autor que lidera en la actualidad esta alternativa es Robinson, que, a través de su concepto de "merecimiento empírico" (es decir, merecimiento según las percepciones sociales de justicia), pretende explicar cómo una pena retributiva alcanza finalidades de prevención de delitos, fundamentalmente mediante el incremento de su capacidad para guiar el cumplimiento normativo de los sujetos (2008: 176-189; 2012: 44; 2013: 152-163). En un sentido muy similar, autores como Walter (2016: 10-14) o Andrissek (2017: 63-149) comienzan a hablar en Europa de "retribución como finalidad de la pena". Y aunque la visión de todos estos autores parte de un compromiso más o menos fuerte con una aproximación

\footnotetext{
${ }^{34}$ Aunque, como ya se ha ido viendo, hay que estar de acuerdo con Peñaranda Ramos cuando afirma que "si se observan con detalle [...] incluso las [posiciones] de Feuerbach, Bentham o Von Liszt (y hasta las de Kant y Hegel, según algunas interpretaciones) podrían ser consideradas en algún sentido como 'teorías mixtas' de la pena" (Peñaranda Ramos, 2015: 287).

${ }^{35}$ Habla originariamente de "retribución negativa", Mackie (1982: 4).

${ }^{36}$ Por ejemplo, Pérez Manzano (1990: 274-275); Roxin (2006: 91-95 y 851-855; 2015: 193-194); Frisch (2012: 41)

${ }^{37}$ La propia denominación proviene de Hart (1968a: 8-13). Sin embargo, una idea muy similar ya se encuentra en Rawls (1955: 4-13).

38 Por ejemplo, Von Hirsch (1993: 34-47); Peñaranda Ramos (2000: 317-318; 2015: 277-280); Silva Sánchez (2015: 21-34 y 68-70); Hörnle (2017: 34-42).
} 
empírica a la teoría de la pena, lo cierto es que esta confluencia entre retribución y consecuencias también se ha elaborado por autores que toman una perspectiva más abstracta, como sucede en el caso de Pawlik, para el cual la pena viene a restablecer el reparto legítimo de libertades entre ciudadanos vulnerado por el delito, consiguiendo así el mantenimiento del orden social (2012: 109-110), y en el de Mañalich, que habla expresamente de "retribución consecuencialista" y destaca la capacidad de la pena merecida para mantener a futuro la autoridad del Derecho (2015: 11-15).

$\mathrm{Y}$, junto con esta posibilidad de construir una teoría mixta de la pena desde la prevención o desde la retribución, se sigue manteniendo en pie con apoyos muy numerosos la teoría de la unión de Roxin, que no pasa por fusionar distintas justificaciones de la pena en una explicación única, sino que otorga un peso especial en cada momento de la pena a una teoría distinta (por lo que más que una teoría unitaria es una teoría parcelada o híbrida): muy resumidamente, en el momento de la amenaza de la pena lo relevante son sus efectos de prevención general; en el momento de la imposición de la misma hay que atender a criterios retributivos o de merecimiento; y durante su ejecución, lo más importante es la prevención especial positiva (2006: 85-95).

\section{Conclusiones}

Aunque se trata de un concepto tan complejo y desarrollado que hace difícil concluir certeramente, creo que la mayoría de autores y autoras que han pensado sobre la teoría de la pena pueden estar de acuerdo, con relación a cada uno de sus elementos, en lo siguiente:

- En cuanto al concepto de 'pena', es infructuoso el intento de construirlo de espaldas a su naturaleza material (mal impuesto de manera voluntaria). Creo además que es también un sentir muy mayoritario en la doctrina, por un lado, la necesidad de su vinculación con la realización previa de un comportamiento jurídicamente desvalorado y considerado como delito; y, por el otro, el reclamo de su naturaleza fuertemente formalizada. A partir de ahí, las demás notas características de este concepto son tremendamente discutidas y discutibles.

- En cuanto a su justificación, quizás lo más pacífico es aceptar que una visión en exceso unilateral del problema lleva a soluciones incorrectas. Por tanto, si la pena puede justificarse es recurriendo a distintos argumentos (tengan distinta o la misma naturaleza -es decir, se mezclen argumentos deontológicos y consecuencialistas, o se mezclen distintas visiones consecuencialistas entre sí-), lo que, de un modo u otro, lleva al predominio de teorías mixtas/unitarias.

Bibliografía

ANDRISSEK, T. (2017), Vergeltung als Strafzweck. Empirisch-soziologische Begründung und kriminalpolitische Folgerungen, Mohr Siebeck, Tübingen.

BECCARIA, C. (1764 -edición de 2008-), De los delitos y de las penas (trad. De las Casas), Tecnos, Madrid.

BENTHAM, J. (1830 -edición de 2009-), The rationale of punishment, Prometheus Books, New York. 
BETEGÓN CARRILLO, J. (1992), La justificación del castigo, Centro de Estudios Políticos y Constitucionales, Madrid.

CARRARA, F. (1870 -edición de 1957-), Programa de Derecho Criminal. Parte General, vol. II (trad. Ortega Torres y Guerrero), Temis, Bogotá.

FEIJOO SÁNCHEZ, B. (2007), Retribución y prevención general. Un estudio sobre la teoría de la pena y las funciones del Derecho penal, BdeF, Montevideo/Buenos Aires.

FEUERBACH, P. J. A. (1799), Revision der Grundsätze und Grundbegriffe des positiven peinlichen Rechts, Hennigschen Buchhandlung, Erfurt.

FEUERBACH, P. J. A. (1847), Lehrbuch des gemeinen in Deutschland gültigen peinlichen Rechts, Buch I, Georg Friedrich Heyer's Verlag, Giessen.

FRISCH, W. (2012), "Sobre el futuro del Derecho penal de la culpabilidad". En: FEIJOO SÁNCHEZ, B. (ed.), Derecho penal de la culpabilidad y neurociencias, Cizur Menor, Civitas Thomson Reuters, pp. 19-70.

GRECO, L. (2009), Lebendiges und Totes in Feuerbachs Straftheorie, Duncker und Humblot, Berlin.

GROCIO, H. (1625 -edición de 1925-), Del Derecho de la guerra y de la paz, Tomo III (trad. de Torrubiano Ripoll), Reus, Madrid.

HART, H. L. A. (1968a), "Prolegomenon to the principles of punishment". En: HART, H. L. A., Punishment and Responsibility. Essays in the Philosophy of Law, Oxford University Press, Oxford, pp. 1-27.

HART, H. L. A. (1968b), "Postscript: Responsibility and retribution". En: HART, H. L. A., Punishment and Responsibility. Essays in the Philosophy of Law, Oxford, Oxford University Press, pp. 210-237.

HASSEMER, W. (2009), Warum Strafe sein muss? Ein Plädoyer, Ullstein Verlag, Leck.

HEGEL, G. W. F. (1821 -edición de 1993-), Grundlinien der Philosophie des Rechts, Suhrkamp, Frankfurt am Main.

HÖRNLE, T. (2017), Straftheorien, $2^{\mathrm{a}}$ ed., Mohr Siebeck, Tübingen.

JAKOBS, G. (1991), Strafrecht. Allgemeiner Teil, $2^{\mathrm{a}}$ ed., De Gruyter, Berlin.

JAKOBS, G. (1997), Norm, Person, Gesellschaft, Duncker und Humblot, Berlin.

JAKOBS, G. (2005), "La pena como reparación del daño". En: REYES ALVARADO, Y. (coord.), Dogmática y Criminología. Dos visiones complementarias del fenómeno delictivo. Homenaje a Alfonso Reyes Echandía, Bogotá, Legis, pp. 339-351.

JAKOBS, G. (2006), La pena estatal: Significado y finalidad (trad. Cancio Meliá y Feijoo Sánchez), Thomson Civitas, Madrid.

JAKOBS, G. (2012), System der strafrechtlichen Zurechnung, Vittorio Klostermann, Frankfurt am Main.

KANT, I. (1797 -edición de 2008-), La metafísica de las costumbres (trad. Cortina Orts y Conill Sancho), Tecnos, Madrid.

KINDHÄUSER, U. (2017), Strafrecht. Allgemeiner Teil, $8^{a}$ ed., Nomos, Baden-Baden.

KLUG, U. (1968), "Abschied von Kant und Hegel". En: BAUMANN, J. (coord.), Programm für ein neues Strafgesetzbuch: Der Alternativ-Entwurf der Strafrechtslehrer, Frankfurt am Main, Fischer Bücherei, pp. 36-41.

LASCURAÍN SÁNCHEZ, J. A. (2009), Sólo penas legales, precisas y previas: El derecho a la legalidad penal en la jurisprudencia constitucional, Aranzadi Thomson Reuters, Cizur Menor.

LASCURAÍN SÁNCHEZ, J. A. (2018), "Penas y adminisanciones". En: SUAREZ LÓPEZ, J. M. et al. (dirs.), Estudios jurídico penales y criminológicos en homenaje al Prof. Dr. Dr. h. c. mult. Lorenzo Morillas Cueva, Madrid, Dykinson, pp. 353-368.

MACKIE, J. L. (1982), "Morality and the retributive emotions", Criminal Justice Ethics, vol. 1, núm. 1, pp. 3-10. 
MAÑALICH, J. P. (2015), "Retribucionismo consecuencialista como programa de ideología punitiva", InDret, núm. 2.

MOLINA FERNÁNDEZ, F. (2002), Responsabilidad jurídica y libertad (una investigación sobre el fundamento material de la culpabilidad), Universidad Externado de Colombia, Bogotá.

MIR PUIG, S. (2011), Bases constitucionales del Derecho penal, lustel, Madrid. (2016), Derecho Penal. Parte General, 10ª ed., Reppertor, Barcelona.

NINO, C. S. (1980 -edición de 2016-), Introducción al análisis del Derecho, Ariel, Barcelona.

NINO, C. S. (1989), "La derivación de los principios de responsabilidad penal de los fundamentos de los derechos humanos", Doctrina Penal, vol. 12, núm. 45, pp. 29-48.

PAWLIK, M. (2012), Das Unrecht des Bürgers. Grundlinien der Allgemeinen Verbrechenslehre, Mohr Siebeck, Tübingen.

PEÑARANDA RAMOS, E. (2000), "Sobre la influencia del funcionalismo y la teoría de sistemas en las actuales concepciones de la pena y del concepto de delito", Doxa, núm. 23, pp. 289-321.

PEÑARANDA RAMOS, E. (2015), "La pena: Nociones generales". En: LASCURAÍN SÁNCHEZ, J. A. (coord.), Introducción al Derecho penal, $2^{\mathrm{a}}$ ed., Madrid, Civitas Thomson Reuters, pp. 255-293.

PÉREZ MANZANO, M. (1990), Culpabilidad y prevención: Las teorías de la prevención general positiva en la fundamentación de la imputación subjetiva y de la pena, Ediciones de la Universidad Autónoma de Madrid, Madrid.

PÉREZ MANZANO, M. (2010), "El recargo de prestaciones sociales y la interdicción constitucional de doble sanción", Actum Social, núm. 44, pp. 29-36.

PLATÓN (384 a.C. -edición de 2010-), Protágoras (trad. García Gual), Gredos, Madrid.

RAWLS, J. (1955), "Two concepts of rules", The Philosophical Review, vol. 64, núm. 1, pp. 3-32.

ROBINSON, P. H. (2008), Distributive principles of Criminal Law. Who should be punished how much?, Oxford University Press, New York.

ROBINSON, P. H. (2012), "El papel que corresponde a la comunidad en la determinación de la responsabilidad penal y de la pena". En: MIR PUIG, S. et al. (dirs.), Constitución y sistema penal, Madrid, Marcial Pons, pp. 41-64.

ROBINSON, P. H. (2013), Intuitions of justice and the utility of desert, Oxford University Press, New York.

RODRÍGUEZ HORCAJO, D. (2013), "Nulla poena sine lege y retroactividad de cambios jurisprudenciales: modificaciones tras la STEDH as. Del Río Prada c. España (21/10/2013)", ADPCP, vol. 64, pp. 251-292.

RODRÍGUEZ HORCAJO, D. (2016), Comportamiento humano y pena estatal: Disuasión, cooperación y equidad, Marcial Pons, Madrid.

ROdRíguez MOURULlO, G. (1978), Derecho Penal. Parte General, Civitas, Madrid.

RODRÍGUEZ MOURULLO, G. (2002), Delito y pena en la jurisprudencia constitucional, Civitas, Madrid.

ROXIN, C. (2006), Strafrecht Allgemeiner Teil, Band I, C. H. Beck, München.

ROXIN, C. (2015), "Prävention, Tadel und Verantwortung. Zur neuesten Strafzweckdiskussion", GA, vol. 162, núm. 4, pp. 185-202.

SILVA SÁNCHEZ, J.-M. (2015), En busca del Derecho penal. Esbozos de una teoría realista del delito y de la pena, BdeF, Buenos Aires.

STRATENWERTH, G. y KUHLEN, L. (2011), Strafrecht. Allgemeiner Teil, $6^{a}$ ed., Franz Vahlen, München.

VON HIRSCH, A. (1993 -edición de 1998-), Censurar y castigar (trad. Larrauri Pijoan), Trotta, Madrid.

VON LISZT, F. (1883), "Der Zweckgedanke im Strafrecht”, ZStW, vol. 3, pp. 1-47. 
WALTER, T. (2016), Strafe und Vergeltung - Rehabilitation und Grenzen eines Prinzips, Nomos/C. H. Beck, München.

ZAIBERT, L. (2015), “La justificación de la pena”, Eunomía, núm. 8, pp. 146-152.

ZAIBERT, L. (2018), Rethinking punishment, Cambridge University Press, Cambridge. 